\section{Leukocytes influence peripheral tissue oxygenation and perfusion in neonates}

\author{
CORINNA BINDER • BERNDT URLESBERGER • REGINA RIEDL • \\ NICHOLAS MORRIS • BERNHARD SCHWABERGER • \\ GERHARD PICHLER
}

\begin{abstract}
Background. Leukocyte counts may influence peripheral (micro) circulation due to changes in rheology. The aim of this study was to investigate a possible association between leukocyte counts and peripheral tissue oxygenation/perfusion measured with near infrared spectroscopy (NIRS) in term and preterm neonates.

Methods. In this observational study we included term and preterm neonates within the first 2 months of life, in whom peripheral tissue NIRS measurements were performed and blood samples (leukocytes and C reactive protein (CRP)) taken to investigate clinical signs of infection. Tissue-oxygenation index (TOI), fractional oxygen extraction (FTEO), oxygen delivery $\left(\mathrm{DO}_{2}\right)$, oxygen consumption $\left(\mathrm{VO}_{2}\right)$ and vascular resistance $(\mathrm{VR})$ were measured by NIRS and venous occlusion method. TOI, FTOE, $\mathrm{DO}_{2}, \mathrm{VO}_{2}$ and VR were correlated to leukocyte counts on the same day and maximal CRP levels within 24 hours (CRP max).

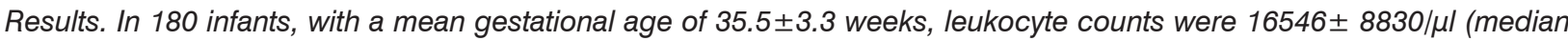
14830; range 1790 to 67840) and CRP max was 8.0 $19.0 \mathrm{mg} / \mathrm{l}$ (median 0.0; range 0.0 to $110.0 \mathrm{mg} / \mathrm{l}$ ).

TOI was $71.1 \pm 5.5 \%$, FTOE $28.5 \pm 6.1 \%, \mathrm{DO}_{2} 46.7 \pm 19.7, \mathrm{VO}_{2} 12.5 \pm 4.4$ and $\mathrm{VR} 11.7 \pm 6.4$.

Leukocyte counts correlated negatively $(r=-0.21 ; p=0.005)$ with TOI and positively $(r=0.17 ; p=0.029)$ with VR. Correlations with CRP max did not reach significance.

Conclusion. We demonstrated that peripheral tissue oxygen consumption decreases and vascular resistance increases with increasing leukocyte counts.
\end{abstract}

Key words: near-infrared spectroscopy, neonate, microcirculation, leukocytes.

\section{Introduction}

Peripheral (micro) circulation is influenced by changes in rheology due to changes in blood cell counts, $(1,2)$ and by cardiovascular (3) and inflammatory processes. $(4,5)$ Symptoms of inflammatory processes, such as hyperthermia, lethargy, tachypnea or poor crying are non-specific in neonates. (6) Therefore, when infection is suspected, in addition to these clinical signs, laboratory parameters may be helpful. C reactive protein (CRP) levels and leukocyte counts are two of the most widely used parameters in routine clinical diagnosis of inflammation and infection. $(6,7)$

To measure changes in peripheral (micro) circulation and oxygenation non-invasively, different devices can be used. (8) Near infrared spectroscopy (NIRS) is one of them, which enables continuous measurement of tissue oxygenation and perfusion. $(9,10)$ Previous studies have described associations between inflammatory processes and peripheral muscle oxygenation in adults. (11-13) Recently, our study group was able to show differences in peripheral oxygenation and perfusion in neonates with CRP elevation. (14)

The aim of this study was to demonstrate a possible association between varying leukocyte counts and peripheral tissue oxygenation/perfusion measured with NIRS in term and preterm neonates. We hypothesized that peripheral oxygenation and perfusion would be impaired in association with increasing leukocyte counts. 


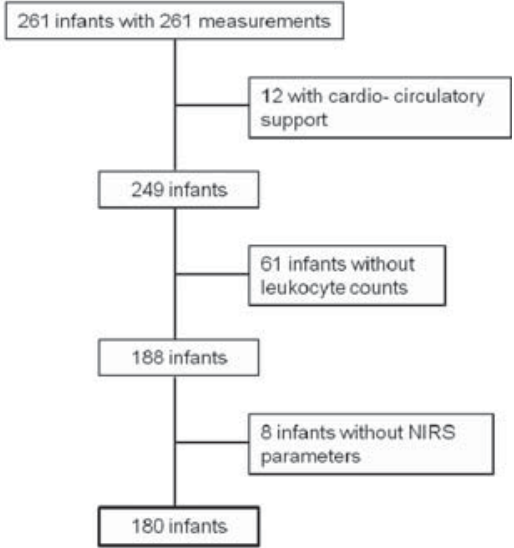

NIRS, near infrared spectroscopy.

Figure 1. Numbers of infants, who were eligible, excluded and included for the study.

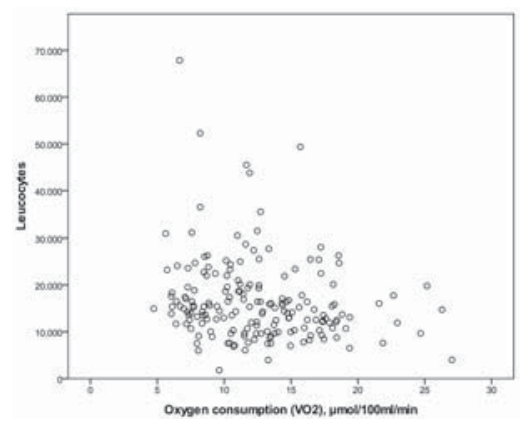

Figure 2. Correlation between leukocytes and peripheral oxygen consumption (VO2) in 180 infants $(r=-0.21 ; p=$ 0.005).

\section{Methods}

Patients

This observational study was conducted at the Medical University of Graz, Division of Neonatology. We included term and preterm neonates within the first 2 months of life in whom peripheral tissue NIRS measurements were performed and blood samples were taken to investigate clinical signs of infection. We excluded neonates with congenital malformations or any cardio-circulatory support. No other specific entry criteria were defined.

Neonates born between January 2006 and February 2011, who satisfied the above criteria, were included.

NIRS measurements were approved by the local ethics committee. Informed consent was obtained from the parents before measurements.

NIRS

Peripheral muscle oxygenation and circulation were measured by NIRS with the venous occlusion method.

NIRS measurements were carried out with the NIRO 300 (Hamamatsu Photonics, Japan). The optodes were attached to the lateral side of the left calf, the interoptode distance was $3.0 \mathrm{~cm}$, and the sampling rate was $2 / \mathrm{sec}$. A differential path length factor of 5.51 was used. (15) The spatially resolved method (NIRO 300) enables non-invasive continuous measurement of the tissue oxygenation index (TOI) and of changes in the concentration of oxygenated haemoglobin $\left(\mathrm{HbO}_{2}\right)$ and deoxygenated haemoglobin $(\mathrm{Hb})$. Changes in the concentration of total haemoglobin $\left(\mathrm{Hb}_{\text {tot }}\right)$ were calculated from the sum of changes in $\mathrm{HbO}_{2}$ and $\mathrm{Hb}$.

Venous occlusion

Venous occlusion was performed using a pneumatic cuff placed around the thigh. Venous occlusion causes an increase in calf blood volume by undisturbed calf arterial (in) flow and interrupted venous (out) flow. Changes in $\mathrm{HbO}_{2}, \mathrm{Hb}$ and $\mathrm{Hb}_{\text {tot }}$ during venous occlusion are only caused by arterial inflow and oxygen consumption of the tissue.

Protocol

A detailed protocol of the measurement and the calculations of the NIRS parameters have been reported in a previous study. (16)

Blood samples

NIRS measurements were performed after routine blood samples were taken to investigate clinical sign/s of infection. Blood cell counts and CRP levels were measured. In neonates with persisting signs of infection a second blood sample was taken within 24 hours of the NIRS measurement.

Statistical analysis

Only data from measurements passing published quality criteria were analysed. (16) The Spearman's rank correlation coefficients were used to assess the correlations between NIRS parameters (tissue oxygenation index, fractional oxygen extraction, oxygen consumption, oxygen delivery, vascular resistance) and leukocyte counts. In addition we calculated the correlation between NIRS parameters and maximal CRP levels (CRP max), whereby in neonates with CRP $\max <0.6 \mathrm{mg} / \mathrm{l}$ the CRP max was set to zero. P-values of $<0.05$ were regarded as statistically significant and of $<0.01$ as highly significant. The statistical analysis was performed using the statistical software SPSS 19.0 (SPSS Inc, Chicago, III).

\section{Results}

From January 2006 to February 2011, 261 infants were included in the study and 180 neonates were analysed (figure 1). Demographic and clinical data of the 180 analysed infants are presented in table 1. Data of peripheral muscle oxygenation and perfusion are shown in table 2.

Leukocyte counts were $16546 \pm 8830 / \mu \mathrm{l}$ (median 14830; range 1790 to 67840). Leukocyte counts correlated negatively $(r=-0.21 ; p=0.005)$ with tissue oxygen consumption $\left(\mathrm{VO}_{2}\right)$ (figure 2 ) and positively $(r=0.17 ; p=0.029)$ with vascular resistance (VR).

CRP max was $8.0 \pm 19.0 \mathrm{mg} / \mathrm{l}$ (median 0.0 ; range 0.0 to $110.0 \mathrm{mg} / \mathrm{l})$. In 114 infants no CRP elevation (CRP < $0.6 \mathrm{mg} / \mathrm{l})$ was measured.

Taking all neonates into account, there was a trend that CRP max correlated negatively with TOI $(p=0.068)$ and with $\mathrm{VO}_{2}(p=0.096)$, without reaching significance.

\section{Discussion}

To our knowledge this is the first study which showed an association between leukocyte counts and peripheral muscle oxygenation and perfusion in term and preterm neonates. We demonstrated that peripheral tissue oxygen consumption decreases and vascular resistance increases with increasing leukocyte counts.

These results suggest alterations in peripheral microcirculation with increasing leukocyte counts, which could be explained by changes in rheology primarily caused by increased leukocyte 
Table 1. Demographic and clinical parameters of the study group.

\begin{tabular}{llllll}
\hline & $\mathrm{n}$ & Mean & SD & Median & Range \\
\hline Gestational age (wk) & 180 & 35.5 & 3.3 & 35.1 & $24.4-42.0$ \\
Birthweight (g) & 179 & 2545 & 847 & 2400 & $700-5400$ \\
Age on day of measurement (h) & 180 & 53 & 146 & 22 & $0-1392$ \\
Actual weight (g) & 175 & 2577 & 797 & 2450 & $760-4480$ \\
Calf diameter (cm) & 177 & 3.0 & 0.5 & 3.0 & $1.7-4.2$ \\
Calf subcutaneous adipose tissue (cm) & 178 & 0.3 & 0.1 & 0.3 & $0.1-0.6$ \\
APGAR 5 & 180 & 9.1 & 1.2 & 9.0 & $2.0-10.0$ \\
HR - heart rate (bpm) & 180 & 129 & 14 & 128 & $93-175$ \\
SpO - oxygen saturation (\%) & 180 & 95.9 & 3.1 & 98.2 & $85.3-100.0$ \\
Mean arterial blood pressure (mmHg) & 167 & 42.3 & 7.4 & 40.0 & $19.5-68.0$ \\
Temperature rectal (celsius) & 164 & 36.9 & 0.3 & 36.9 & $35.9-37.9$ \\
Temperature peripheral (celsius) & 179 & 35.4 & 0.9 & 35.6 & $32.5-37.6$ \\
Central capillary refill time (sec) & 178 & 3.2 & 0.8 & 3.1 & $1.3-7.1$ \\
Peripheral capillary refill time (sec) & 178 & 3.1 & 0.6 & 3.0 & $1.4-5.3$ \\
\hline
\end{tabular}

Table 2. Peripheral muscle oxygenation and perfusion measured with near infrared spectroscopy (NIRS) in 180 infants.

\begin{tabular}{llllll}
\hline & $\mathrm{n}$ & Mean & SD & Median & Range \\
\hline Tissue oxygenation index (TOI), \% & 180 & 71.1 & 5.5 & 71.8 & $48.9-85.0$ \\
Fractional oxygen extraction (FOE), \% & 180 & 28.5 & 6.1 & 28.0 & $15.0-50.4$ \\
Oxygen delivery $\left(\mathrm{DO}_{2}\right), \mu \mathrm{mol} / 100 \mathrm{ml} / \mathrm{min}$ & 180 & 46.7 & 19.7 & 45.3 & $14.9-110.4$ \\
Oxygen consumption $\left(\mathrm{VO}_{2}\right), \mu \mathrm{mol} / 100 \mathrm{ml} / \mathrm{min}$ & 180 & 12.5 & 4.4 & 11.9 & $4.7-27.0$ \\
Vascular resistance $(\mathrm{VR}), \mathrm{mmHg} / \mathrm{ml} / \mathrm{min}$ & 157 & 11.7 & 6.4 & 9.9 & $2.8-38.6$ \\
\hline
\end{tabular}

count. Because of their large volume and low deformability (17), white blood cells can influence the microcirculatory flow even though their total volume concentration is much lower, in comparison to red blood cells. (1) The Influence of $\mathrm{Hb}$ on peripheral oxygenation and perfusion has already been demonstrated using NIRS in several studies. (18-20) Increasing leukocyte counts with changes in peripheral oxygenation and perfusion might be associated with inflammatory processes. Studies have demonstrated associations between inflammatory processes and changes in the microcirculation. $(4,5,21)$ It is known that inflammation can cause decreased deformability, accumulation and increased endothelial cell adhesion of leukocytes, which can lead to capillary plugging and organ/tissue ischemia. (22-25)

Adults with septic conditions had significant changes in $\mathrm{VO}_{2}$ measured with NIRS. $\mathrm{VO}_{2}$ was lower in patients with SIRS (13) and correlated negatively with inflammatory markers. (12) These findings are in accordance with our results in $\mathrm{VO}_{2}$ in neonates.

In a previous study we demonstrated that neonates with elevated CRP levels have reduced peripheral tissue oxygenation and perfusion. (14) In the present study there were only trends but no significant correlations between CRP max and NIRS parameters. This finding is most probably due to the fact that in 114 of 180 infants CRP was negative $(<0.6 \mathrm{mg} / \mathrm{l})$. Moreover, this finding supports the hypothesis that leukocyte levels themselves are associated with changes in peripheral oxygenation and perfusion.

The present study has some shortcomings. First of all, the study population 
was rather heterogeneous, and correlations were rather weak. Therefore, the clinical significance of these findings must be interpreted with caution. Nevertheless, correlations between leukocyte counts and $\mathrm{VO}_{2} \mathrm{NR}$ were significant, even though other parameters are known to influence peripheral oxygenation and perfusion. (18-20,26-29)

This study further contributes to the understanding of changes in oxygenation and perfusion in the peripheral tissue of newborn infants. The technique of NIRS is improving constantly and has the potential to become a useful, noninvasive diagnostic bedside tool with the ability to measure subtle disturbances in oxygenation and perfusion in peripheral tissue, before vital organs are affected, in order to initiate appropriate therapy at an earlier stage.

\section{ACKNOWLEDGMENTS}

We would like to express our gratitude to the parents for consenting to enroll their infants in our study, and to our team of midwives, nurses and physicians involved in their care. We also thank Professor Andrea Berghold (Institute for Medical Informatics, Statistics and Information, Medical University Graz) for statistical analysis and Evelyne Ziehenberger for her assistance in completing the study.

\section{REFERENCES}

1. Braide M, Amundson B, Chien S, Bagge U. Quantitative studies on the influence of leukocytes on the vascular resistance in a skeletal muscle preparation. Microvasc Res 1984;27:331-52.

2. Norman M, Fagrell B, Herin P. Skin microcirculation in neonatal polycythaemia and effects of haemodilution. Interaction between haematocrit, vasomotor activity and perfusion. Acta Paediatr 1993;82:672-7.

3. Stark MJ, Clifton VL, Wright IM. Microvascular flow, clinical illness severity and cardiovascular function in the preterm infant. Arch Dis Child Fetal Neonatal Ed 2008; 93:F271-4.

4. Top AP, Tasker RC, Ince C. The microcirculation of the critically ill pediatric patient. Crit Care 2011;15:213.

5. Ince C. The microcirculation is the motor of sepsis. Crit Care 2005; 9 Suppl 4:S13-9.

6. Stefanovic IM. Neonatal sepsis. Biochem Med 2011;21:276-81.

7. Caldas JP, Marba ST, Blotta MH, Calil R, Morais SS, Oliveira RT. Accuracy of white blood cell count, C-reactive protein, interleukin-6 and tumor necrosis factor alpha for diagnosing late neonatal sepsis. J Pediatr (Rio J) 2008;84:536-42.

8. Lima A, Bakker J. Noninvasive monitoring of peripheral perfusion. Intensive Care Med 2005;31:1316-26.

9. Wolf M, Ferrari M, Quaresima V. Progress of near-infrared spectroscopy and topography for brain and muscle clinical applications. J Biomed Opt 2007;12:62104.

10. Weindling AM. Peripheral oxygenation and management in the perinatal period. Semin Fetal Neonatal Med 2010;15:208-15.

11. De BRA, Palmisani S, Alampi D, Mercieri M, Romano R, Collini S, et al. Microvascular dysfunction and skeletal muscle oxygenation assessed by phase-modulation near-infrared spectroscopy in patients with septic shock. Intensive Care Med 2005;31:1661-8.

12. Kullo IJ, Khaleghi M, Hensrud DD. Markers of inflammation are inversely associated with VO2 max in asymptomatic men. J Appl Physiol 2007;102:1374-9.

13. Nanas S, Gerovasili V, Renieris P, Angelopoulos E, Poriazi M, Kritikos K, et al. Non-invasive assessment of the microcirculation in critically ill patients. Anaesth Intensive Care 2009;37:733-9.

14. Pichler G, Pocivalnik M, Riedl R, Pichler-Stachl E, Zotter H, Müller W, et al. C reactive protein: impact on peripheral tissue oxygenation and perfusion in neonates. Arch Dis Child Fetal Neonatal Ed 2012; doi:10.1136/archdischild-2011-300578.

15. Duncan A, Meek JH, Clemence M, Elwell CE, Tyszczuk L, Cope M, et al. Optical pathlength measurements on adult head, calf and forearm and the head of the newborn infant using phase resolved optical spectroscopy. Phys Med Biol 1995;40:295-304.

16. Pichler G, Grossauer K, Peichl E, Gaster A, Berghold A, Schwantzer G, et al. Combination of different noninvasive measuring techniques: a new approach to increase accuracy of peripheral near infrared spectroscopy. J Biomed Opt 2009;14:14014

17. Miller ME, Myers K. Cellular deformability of the human peripheral blood polymorphonuclear leukocyte: method of study, normal variation and effects of physical and chemical alterations. J Reticuloendothel Soc 1975;18:337-45.

18. Pichler G, Pocivalnik M, Riedl R, Pichler-Stachl E, Morris N, Zotter H, et al. ŽMulti-associations': predisposed to misinterpretation of peripheral tissue oxygenation and circulation in neonates. Physiol Meas 2011;32:1025-34.

19. Wardle SP, Yoxall CW, Crawley E, Weindling AM. Peripheral oxygenation and anemia in preterm babies. Pediatr Res 1998;44:125-31.

20. Kissack CM, Weindling AM. Peripheral blood flow and oxygen extraction in the sick, newborn very low birth weight infant shortly after birth. Pediatr Res 2009;65:462-7.

21. Bateman RM, Sharpe MD, Ellis CG. Bench-to-bedside review: microvascular dysfunction in sepsis--hemodynamics, oxygen transport, and nitric oxide. Crit Care 2003:7:359-73

22. Yodice PC, Astiz ME, Kurian BM, Lin RY, Rackow EC. Neutrophil rheologic changes in septic shock. Am J Respir Crit Care Med 1997; 155:38-42.

23. Nishino M, Tanaka H, Ogura H, Inoue Y, Koh T, Fujita K, et al. Serial changes in leukocyte deformability and whole blood rheology in patients with sepsis or trauma. J Trauma 2005;59:1425-31.

24. Haslett C, Worthen GS, Giclas PC, Morrison DC, Henson JE, Henson PM. The pulmonary vascular sequestration of neutrophils in endotoxemia is initiated by an effect of endotoxin on the neutrophil in the rabbit. Am Rev Respir Dis 1987;136:9-18.

25. Worthen GS, Schwab B3, Elson EL, Downey GP. Mechanics of stimulated neutrophils: cell stiffening induces retention in capillaries. Science 1989;245:183-6.

26. Hassan IA, Wickramasinghe YA, Spencer SA. Effect of a change in global metabolic rate on peripheral oxygen consumption in neonates. Arch Dis Child Fetal Neonatal Ed 2003; 88:F143-6.

27. Hassan IA, Wickramasinghe YA, Spencer SA. Effect of limb cooling on peripheral and global oxygen consumption in neonates. Arch Dis Child Fetal Neonatal Ed 2003;88:F139-42.

28. Victor S, Marson AG, Appleton RE, Beirne M, Weindling AM. Relationship between blood pressure, cerebral electrical activity, cerebral fractional oxygen extraction, and peripheral blood flow in very low birth weight newborn infants. Pediatr Res 2006; 59:314-9.

29. Wardle SP, Yoxall CW, Weindling AM. Peripheral oxygenation in hypotensive preterm babies. Pediatr Res 1999;45:343-9. 